\title{
Marital Status and Colon Cancer Stage at Diagnosis
}

\author{
Kuan-Chi Lai* and Brie A. Stotler
}

Columbia University Mailman School of Public Health, 722 West 168th Street, New York, NY 10032, USA

\begin{abstract}
This study evaluated the association between marital status and colon cancer survival in SEER cancer registrants to determine if the survival benefit of married patients is due to earlier stage at diagnosis. The adjusted analysis that included stage at diagnosis showed $23 \%$ higher risk of death in single patients compared to married patients, which decreased from $28 \%$ in the unadjusted analysis. Unmarried patients were more likely to be diagnosed in later stages with adjusted odds ratios for single of 1.11 [95\% CI: 1.06-1.16]. Married patients were more likely to be diagnosed at earlier stages, suggesting increased use of screening programs. The survival benefit for married patients compared to unmarried decreased when stage was controlled, suggesting marital status is associated with survival through its impact on stage.
\end{abstract}

Keywords: Marital status, colon cancer, diagnosis stage, survival, SEER.

\section{INTRODUCTION}

Colon cancer is the third most common cancer with an estimated 106,100 new cases in 2009 in the United States [1] and is among the top three causes of cancer mortality. Although the overall 5-year survival is $64 \%$ (including rectal cancer), survival rate varies greatly with stage of disease at diagnosis [1]. The 5-year survival can be as high as $90 \%$ for patients whose disease is detected at an early and localized stage, however, patients that are diagnosed with distant metastases have only a $11 \%$ 5-year survival [1].

When diagnosed at an early stage, colorectal cancer can be cured with surgical resection. However, only $40 \%$ of colorectal cancers are diagnosed at an early stage [1], prompting advocacy for the better use of screening. The U.S. Preventive Services Task Force recommends screening using fecal occult blood testing, sigmoidoscopy, or colonoscopy in adults between age of 50 to 75 years [2]. Despite the recommendation, screening remains underused. A study of 1,088 patients who underwent colonoscopy found that $65 \%$ did so because of symptomatic disease, while only $35 \%$ had an exam solely for the purpose of screening [3].

Several studies have investigated factors associated with increased likelihood of colon cancer screening including older age, higher education and income level, available health insurance, and being married [3-7]. Married people are more likely to participate in colon cancer screening [8] and also more likely to receive colonoscopy recommendation from physicians [7]. Since many studies have shown marital status is significantly associated with colon cancer survival [9-14], we hypothesized that the observed survival benefit of being married for colon cancer patients is due to the higher likelihood of early diagnosis secondary to participation in routine colon cancer screening. This study used a population-based dataset from the Surveillance Epidemiology and End Results (SEER) Program to compare colon

*Address correspondence to this author at the Columbia University Mailman School of Public Health, 722 West 168th Street, New York, NY 10032, USA; kuanchi1013@gmail.com cancer sur vival and stage at diagnosis among married and unmarried patients.

\section{METHODS}

The SEER Program was used to identify the patient population selection criteria from a published report [15] on colon cancer survival. Patients were selected that had a primary cancer site limited to the colon (cecum, ascending colon, hepatic flexure, transverse colon, splenic flexure, descending colon, sigmoid colon, and large intestine not otherwise specified) and a histologic type limited to adenocarcinoma, mucinous adenocarcinoma, and signet ring cell carcinoma $(8010,8020-8022,8140-8145,8210-8211,8220-8221$, $8230-8231,8260-8263,8470,8480-8481$, and 8490 codes from International Classification of Disease for Oncology, Second Edition [ICD-O-2]). The population was further restricted to patients diagnosed between 1992 and 2003 to ensure at least 2 years of follow-up before the 2005 cut off in the SEER database. Furthermore, only patients between age 50 and 75 at diagnosis were included in analysis because screening for colorectal cancer is recommended in this age range [2]. Finally, the analysis included only primary malignancy cases with known marital status and stage at diagnosis.

Only 'colon excluding rectum' as cause of death was considered an event while all other causes of death were censored in the survival analysis. Tumors were staged according to the American Joint Committee on Cancer (AJCC) Sixth Edition staging system into 7 stages based on tumor-nodemetastasis (TNM) [16]. The TNM classification of each case was determined by SEER data on extent of disease. Tumor grade information was directly available from SEER. Patient demographic information included marital status, gender, race, birth place, age, and socioeconomic status. Since individual socioeconomic status (SES) is unavailable from SEER, we followed the common practice $[17,18]$ of using the 2000 United States Census county of residence data to obtain county-level income by race (percent of families above federal poverty level), county-level education by race 
(percent of people graduated from high school), and countylevel status by race (percent of white collar jobs).

$\chi^{2}$ test in contingency table and $F$ test in ANOVA was used to test the significance of association between marital status and other variables. Kaplan-Meier method was used to estimate the survival and the log rank test was used to determine the significance of differences among the survival curves. Cox proportional hazard model was used for unadjusted and adjusted regression analysis. Adjusted survival analyses included marital status, stage, grade, site, gender, race, birth place, age, and SES. Logistic regression with cumulative logit model was used to assess the association between the ordinal outcome (stage at diagnosis) and the explanatory variables. Adjusted logistic regression included marital status, grade, site, gender, race, birth place, age, and SES. All tests were two-sided and considered to be statistically significant if $p<0.05$. All statistical analyses were performed using SAS software, Version 9.1 (copyright (C) 20022003 SAS Institute Inc., Cary, NC, USA).

\section{RESULTS}

72,214 patients were identified according to the eligibility criteria. $65 \%$ were married, $11 \%$ were single, $9 \%$ were divorced, $1 \%$ were separated, and $14 \%$ were widowed. Table 1 shows the demographic variables which were all highly associated with marital status $(\mathrm{p}<0.0001)$. There were more married males $(75 \%)$ than married females $(55 \%)$. Black non-Hispanic had the lowest proportion of being married $(47 \%)$ whereas all other race groups had at least $63 \%$ of married persons. Foreign born had higher proportion of being married (70\%) compared to US born (63\%). Married patients have consistently higher income, education, and status than single, divorced, separated, or widowed patients.

Unmarried patients (single, divorced, separated, or widowed) had worse survival curves than married patients (Fig. 1). The 5-year survival rate for married patients was $68 \%$ and was between $59-64 \%$ for unmarried patients. Single patients had $23 \%$ higher risk of death after adjusting for possible confounders including tumor stage and grade at diagnosis (Table 2). Adjusted analysis also showed that female (HR: 0.95 [0.92-0.98]), Asian (HR: 0.95 [0.92-0.98]), and foreign born patients (HR: 0.76 [0.73-0.80]) had better survival. Older age and higher tumor grade were associated with worse survival. Higher SES (education, income, and status) had a significant, but very small protective effect on survival only in the unadjusted analysis.

Table 1. Distribution of Colon Cancer Primary Malignancy Cases Diagnosed in 1992-2003 from SEER by Marital Status

\begin{tabular}{|c|c|c|c|c|c|c|c|}
\hline Marital Status & Total & Married & Single & Divorced & Separated & Widowed & P-value \\
\hline Total, n (\%) & $72214(100)$ & $47172(65)$ & $7779(11)$ & $6738(9)$ & $564(1)$ & $9961(14)$ & \\
\hline Gender & & & & & & & $<0.001^{\mathrm{a}}$ \\
\hline Male & $38039(53)$ & $28458(75)$ & $4214(11)$ & $2960(8)$ & $290(1)$ & $2117(6)$ & \\
\hline Female & 34175 (47) & $18714(55)$ & $3565(10)$ & $3778(11)$ & $274(1)$ & $7844(23)$ & \\
\hline Race & & & & & & & $<0.001^{\mathrm{a}}$ \\
\hline White Non-Hispanic & $52625(73)$ & $35576(68)$ & $4875(9)$ & $4685(9)$ & $278(1)$ & $7211(14)$ & \\
\hline Black Non-Hispanic & $8369(12)$ & $3969(47)$ & $1685(20)$ & $1148(14)$ & $180(2)$ & $1387(17)$ & \\
\hline Hispanic & $5296(7)$ & $3359(63)$ & $657(12)$ & $568(11)$ & $69(1)$ & $643(12)$ & \\
\hline Asian & $5414(7)$ & $3925(72)$ & $497(9)$ & $299(6)$ & $32(1)$ & $661(12)$ & \\
\hline Native American & $349(0)$ & $236(68)$ & $42(12)$ & $26(7)$ & $4(1)$ & $41(12)$ & \\
\hline Unknown & $161(0)$ & $107(66)$ & $23(14)$ & $12(7)$ & $1(1)$ & $18(11)$ & \\
\hline Birth Place & & & & & & & $<0.001^{\mathrm{a}}$ \\
\hline USA & $35713(49)$ & $22376(63)$ & $4024(11)$ & $3732(10)$ & $322(1)$ & $5259(15)$ & \\
\hline Foreign & $7275(10)$ & $5066(70)$ & $645(9)$ & $520(7)$ & $62(1)$ & $982(13)$ & \\
\hline Unknown & $29226(40)$ & $19730(68)$ & $3110(11)$ & $2486(9)$ & $180(1)$ & $3720(13)$ & \\
\hline Age, Mean $\left(\mathrm{SD}^{c}\right)$ & $65.13(7.11)$ & $64.81(7.07)$ & $63.55(7.49)$ & $63.55(7.15)$ & $63.06(7.23)$ & $69.05(5.38)$ & $<0.001^{\mathrm{b}}$ \\
\hline Income $^{\mathrm{d}}$, Mean (SD) & $92.08(6.97)$ & $92.58(6.48)$ & $90.28(8.39)$ & $91.36(7.37)$ & $87.48(9.12)$ & $91.89(7.15)$ & $<0.001^{\mathrm{b}}$ \\
\hline Education $^{\mathrm{e}}$, Mean (SD) & $83.16(11.66)$ & 83.57 (11.45) & 81.48 (12.59) & $82.85(12.05)$ & $78.19(13.92)$ & $82.98(11.32)$ & $<0.001^{\mathrm{b}}$ \\
\hline Status ${ }^{\mathrm{f}}$, Mean (SD) & $38.35(10.87)$ & $38.61(10.68)$ & $37.75(11.81)$ & $38.22(11.06)$ & $34.92(11.10)$ & $37.83(10.77)$ & $<0.001^{\mathrm{b}}$ \\
\hline
\end{tabular}

${ }^{\mathrm{a}} \chi^{2}$ test.

${ }^{\mathrm{b}} \mathrm{F}$ test.

${ }^{\mathrm{c}} \mathrm{SD}=$ standard deviation

${ }^{\mathrm{d}}$ Income $=$ county-level percent of families above federal poverty level by race.

${ }^{\mathrm{e}}$ Education $=$ county-level percent of people graduated from high school by race.

${ }^{\mathrm{f}}$ Status $=$ county-level percent of white-collar jobs by race. 


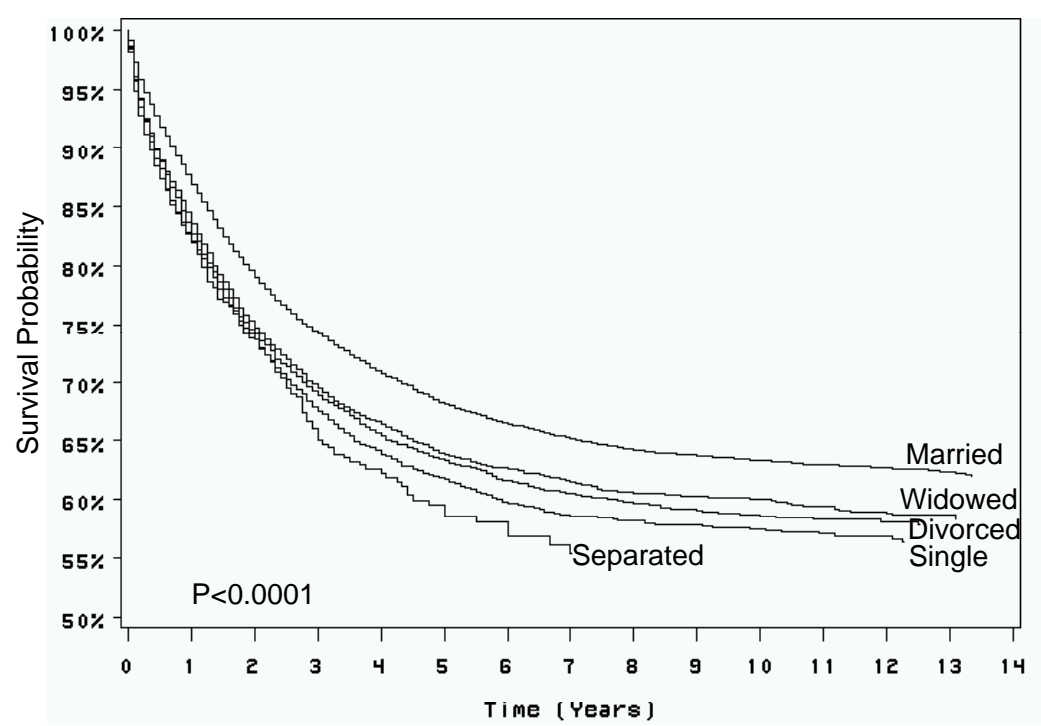

Fig. (1). Overall Survival Stratified by Marital Status.

Table 2. Unadjusted and Adjusted Survival Analysis in Colon Cancer Cases

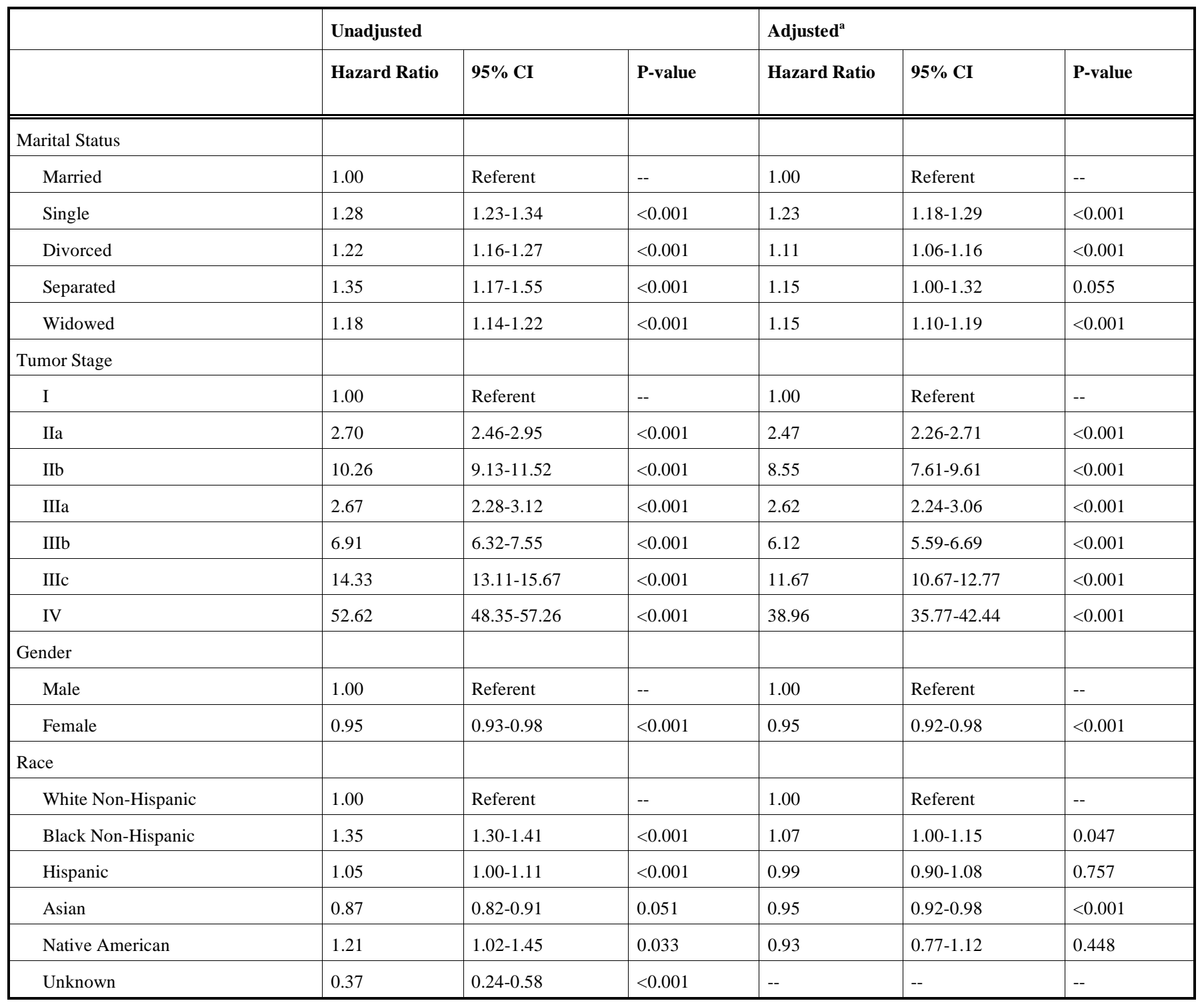


(Table 2). Contd.....

\begin{tabular}{|c|c|c|c|c|c|c|}
\hline & \multicolumn{3}{|l|}{ Unadjusted } & \multicolumn{3}{|l|}{ Adjusted $^{\mathrm{a}}$} \\
\hline \multicolumn{7}{|l|}{ Site } \\
\hline Not Specified & 1.00 & Referent & -- & 1.00 & Referent & -- \\
\hline Ascending Colon & 0.36 & $0.34-0.39$ & $<0.001$ & 0.90 & $0.84-0.97$ & 0.005 \\
\hline Hepatic Flexure & 0.39 & $0.36-0.42$ & $<0.001$ & 1.00 & $0.92-1.09$ & 0.919 \\
\hline Transverse Colon & 0.36 & $0.34-0.39$ & $<0.001$ & 0.88 & $0.82-0.95$ & 0.002 \\
\hline Splenic Flexure & 0.43 & $0.39-0.46$ & $<0.001$ & 0.91 & $0.83-0.99$ & 0.032 \\
\hline \multicolumn{7}{|l|}{ Grade $^{\mathrm{b}}$} \\
\hline Grade I & 1.00 & Referent & -- & 1.00 & Referent & -- \\
\hline Grade II & 1.64 & $1.54-1.75$ & $<0.001$ & 1.13 & $1.06-1.21$ & $<0.001$ \\
\hline Grade III & 3.30 & $3.09-3.53$ & $<0.001$ & 1.61 & $1.51-1.73$ & $<0.001$ \\
\hline Grade IV & 3.95 & $3.44-4.55$ & $<0.001$ & 2.02 & $1.76-2.33$ & $<0.001$ \\
\hline Unknown & 4.38 & $4.07-4.72$ & $<0.001$ & 1.86 & $1.73-2.01$ & $<0.001$ \\
\hline \multicolumn{7}{|l|}{ Birth Place } \\
\hline Income & 0.989 & $0.987-0.991$ & $<0.001$ & 0.993 & $0.989-0.998$ & 0.005 \\
\hline Status & 0.996 & $0.995-0.997$ & $<0.001$ & 0.999 & $0.997-1.002$ & 0.613 \\
\hline
\end{tabular}

adjusted model included marital status, stage, grade, site, gender, race, birth place, age, education, income, and status.

${ }^{\mathrm{b}}$ Grade I = well differentiated, Grade II = moderately differentiated, Grade III = poorly differentiated, Grade IV = undifferentiated

Fig. (2) and Table 2 show the survival rates of the different AJCC stages, which show findings similar to those published in a previous report [15]. Although the survival did not follow the exact order of the progressing stage, Stage I had the best survival (5-year survival: $96 \%$ ) and metastatic Stage IV had the worst survival (5-year survival: 10\%). Stage IIa and IIIa had almost identical survival, followed by Stages IIIb, IIb, and IIIc. Since the primary interest was the effect of marital status on the stage of diagnosis, we reordered the stages according to their rank in survival (I, IIa, IIIa, IIIb, IIb, IIIc, and IV) to represent the ordinal response in tumor survival stages in the cumulative logit model.

Marital status was significantly associated with stage at diagnosis as shown in unadjusted and adjusted models in both AJCC stages (tumor stage) and stages according to survival (survival stage) (Table 3). The unadjusted analysis of tumor stage showed single patients had an OR of 1.18 [1.13-
1.23] compared to married patients diagnosed at later stages. When confounders were controlled, this OR decreased to 1.09 [1.04-1.13], but was still significant in the adjusted analysis. Using the survival curve as the order of stages, single patients had a $11 \%$ higher chance of later diagnosis compared to married patients in the adjusted analysis. Other types of unmarried status were also at an elevated risk of diagnosis in later stages with adjusted ORs of survival stage for divorced, widowed, and separated of 1.08 [1.03-1.13], 1.06 [1.02-1.11], and 1.05 [0.90-1.22], respectively.

Several other demographic variables were predictive of diagnosis in later stages. Female patients (3\% increase), black non-Hispanic (14\% increase) and Hispanic patients (13\% increase) were at an increased risk whereas foreign born had a less likelihood of diagnosis at later stage (adjusted OR: 0.83 [0.79-0.87]). Patients 10 years younger had 


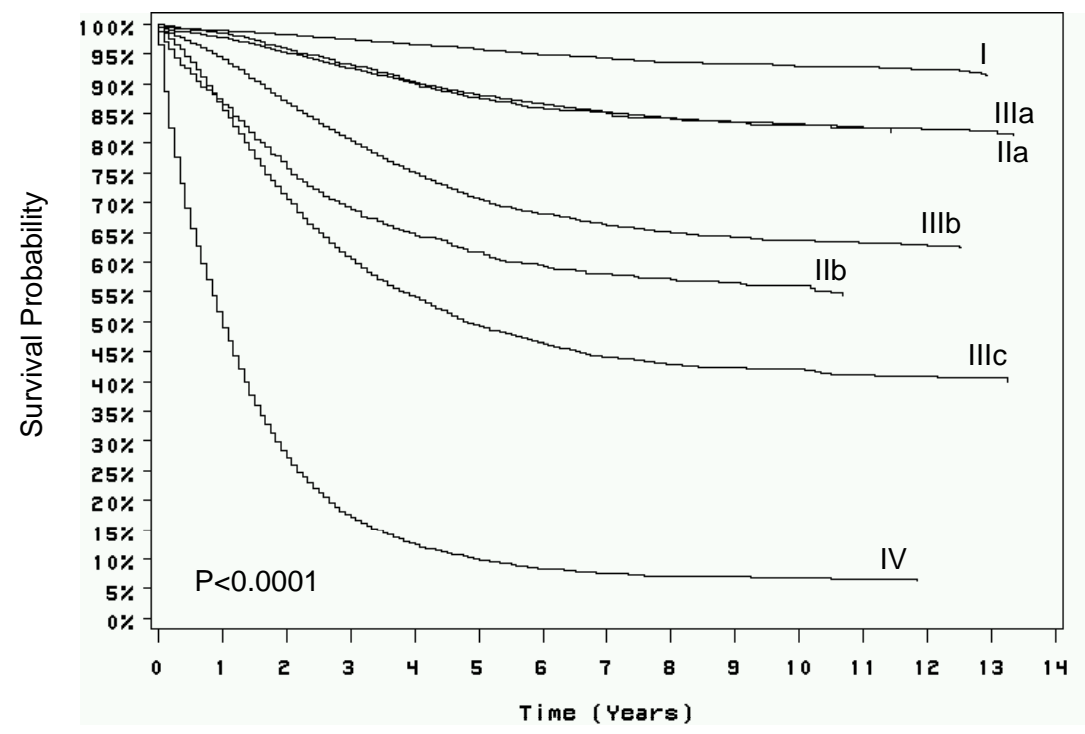

Fig. (2). Overall Survival Stratified by AJCC Stage at Diagnosis.

Table 3. Unadjusted and Adjusted Cumulative Logit Logistic Regression for Colon Cancer Cases

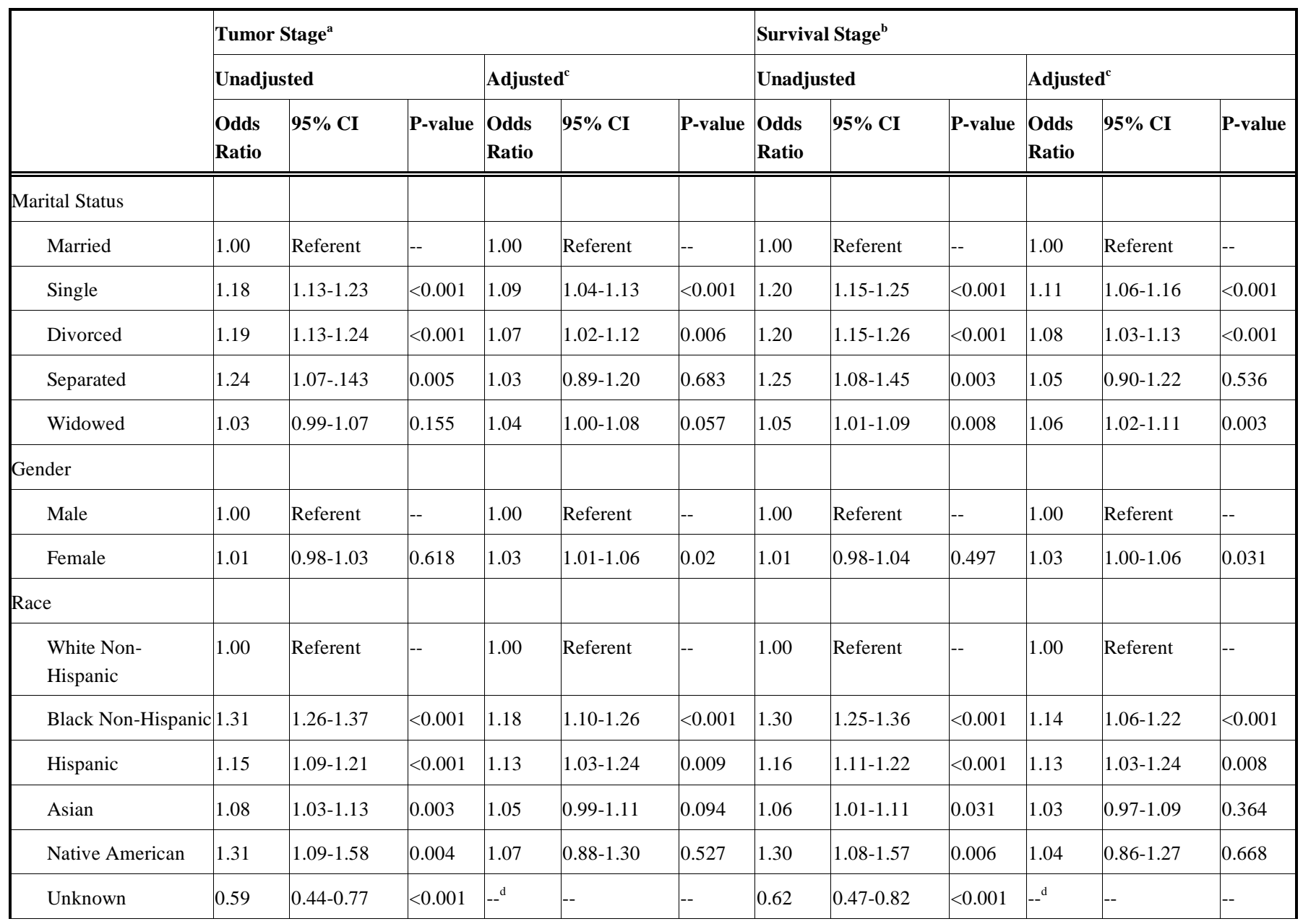


(Table 3). Contd.....

\begin{tabular}{|c|c|c|c|c|c|c|c|c|c|c|c|c|}
\hline & \multicolumn{6}{|c|}{ Tumor Stage $^{\mathrm{a}}$} & \multicolumn{6}{|c|}{ Survival Stage $^{b}$} \\
\hline & \multicolumn{3}{|c|}{ Unadjusted } & \multicolumn{3}{|c|}{ Adjusted $^{\mathrm{c}}$} & \multicolumn{3}{|c|}{ Unadjusted } & \multicolumn{3}{|c|}{ Adjusted $^{\mathrm{c}}$} \\
\hline & $\begin{array}{l}\text { Odds } \\
\text { Ratio }\end{array}$ & $95 \% \mathrm{CI}$ & P-value & $\begin{array}{l}\text { Odds } \\
\text { Ratio }\end{array}$ & $95 \% \mathrm{CI}$ & P-value & $\begin{array}{l}\text { Odds } \\
\text { Ratio }\end{array}$ & $95 \% \mathrm{CI}$ & P-value & $\begin{array}{l}\text { Odds } \\
\text { Ratio }\end{array}$ & $95 \% \mathrm{CI}$ & P-value \\
\hline \multicolumn{13}{|l|}{ Site } \\
\hline Not Specified & 1.00 & Referent & -- & 1.00 & Referent & -- & 1.00 & Referent & -- & 1.00 & Referent & -- \\
\hline Cecum & 0.23 & $0.21-0.25$ & $<0.001$ & 0.25 & $0.23-0.28$ & $<0.001$ & 0.22 & $0.20-0.24$ & $<0.001$ & 0.25 & $0.22-0.27$ & $<0.001$ \\
\hline Ascending Colon & 0.18 & $0.16-0.19$ & $<0.001$ & 0.20 & $0.18-0.22$ & $<0.001$ & 0.18 & $0.16-0.19$ & $<0.001$ & 0.20 & $0.18-0.22$ & $<0.001$ \\
\hline Hepatic Flexure & 0.19 & $0.17-0.21$ & $<0.001$ & 0.21 & $0.19-0.23$ & $<0.001$ & 0.19 & $0.17-0.21$ & $<0.001$ & 0.21 & $0.19-0.23$ & $<0.001$ \\
\hline Transverse Colon & 0.19 & $0.17-0.20$ & $<0.001$ & 0.20 & $0.19-0.22$ & $<0.001$ & 0.19 & $0.17-0.21$ & $<0.001$ & 0.20 & $0.19-0.23$ & $<0.001$ \\
\hline Splenic Flexure & 0.22 & $0.20-0.24$ & $<0.001$ & 0.24 & $0.21-0.26$ & $<0.001$ & 0.22 & $0.20-0.24$ & $<0.001$ & 0.23 & $0.21-0.26$ & $<0.001$ \\
\hline Descending Colon & 0.19 & $0.17-0.21$ & $<0.001$ & 0.20 & $0.18-0.22$ & $<0.001$ & 0.19 & $0.17-0.20$ & $<0.001$ & 0.20 & $0.18-0.22$ & $<0.001$ \\
\hline Sigmoid Colon & 0.18 & $0.16-0.19$ & $<0.001$ & 0.19 & $0.18-0.21$ & $<0.001$ & 0.17 & $0.15-0.18$ & $<0.001$ & 0.18 & $0.17-0.20$ & $<0.001$ \\
\hline \multicolumn{13}{|l|}{ Birth Place } \\
\hline USA & 1.00 & Referent & -- & 1.00 & Referent & -- & 1.00 & Referent & -- & 1.00 & Referent & -- \\
\hline Foreign & 0.83 & $0.80-0.87$ & $<0.001$ & 0.83 & $0.79-0.87$ & $<0.001$ & 0.83 & $0.79-0.87$ & $<0.001$ & 0.83 & $0.79-0.87$ & $<0.001$ \\
\hline Unknown & 0.41 & $0.40-0.42$ & $<0.001$ & 0.41 & $0.40-0.42$ & $<0.001$ & 0.40 & $0.39-0.42$ & $<0.001$ & 0.41 & $0.39-0.42$ & $<0.001$ \\
\hline Age & 0.983 & $0.981-0.985$ & $<0.001$ & 0.980 & $0.978-0.981$ & $<0.001$ & 0.98 & $0.982-0.986$ & $<0.001$ & 0.98 & $0.978-0.982$ & $<0.001$ \\
\hline Education & 0.996 & $0.995-0.997$ & $<0.001$ & 1.002 & $0.998-1.005$ & 0.366 & 1.00 & $0.995-0.997$ & $<0.001$ & 1.00 & $0.998-1.005$ & 0.439 \\
\hline Income & 0.990 & $0.988-0.002$ & $<0.001$ & 1.000 & $0.995-1.005$ & 0.980 & 0.99 & $0.988-0.992$ & $<0.001$ & 1.00 & $0.994-1.003$ & 0.594 \\
\hline Status & 0.996 & $0.995-0.997$ & $<0.001$ & 0.999 & $0.997-1.001$ & 0.789 & 1.00 & $0.995-0.997$ & $<0.001$ & 1.00 & $0.998-1.002$ & 0.951 \\
\hline
\end{tabular}

${ }^{\text {a }}$ stages ordered according to AJCC.

bstages ordered according to survival.

'adjusted model included marital status, grade, site, gender, race, birth place, age, education, income, and status.

${ }^{d}$ cases with unknown race were automatically excluded from the multivariate regression because none of them have a SES value.

a $22 \%$ higher chance of later stage at diagnosis (calculated from the beta estimate of $-0.0199 /$ year). Since age 65 and older patients have Medicare that covers colorectal cancer screening [4], this may confound the analysis. However, we stratified the analysis to $<65$ years old and $\geq 65$ years old and the result did not change from the combined analysis.

\section{DISCUSSION}

Similar to the previous finding that marital status is associated with cancer mortality, including colorectal cancer [914], this study also demonstrates a modest yet significant survival benefit for married patients with colon cancer. Marital status may be a factor in the differences in access to health care and treatment. It has been reported that married people are more likely to be diagnosed early when symptoms are observed $[19,20]$ and also less likely to be delayed in treatment once a diagnosis is made [21]. Furthermore, marital status has been found to be a significant factor in colon cancer screening [8] and cervical cancer screening [22]. A study in the United Kingdom found co-invitation for colorectal cancer screening significantly increased the attendance for both partners [8].

In this study, the survival benefit for married patients compared to unmarried decreased when stage at diagnosis was controlled, suggesting marital status is associated with survival partly through its impact on stage. Married patients were more likely to be diagnosed at early stages (defined either by AJCC or by survival order) compared to unmarried, similar to the findings in breast cancer [23, 24], prostate cancer [24], and melanoma [18]. This finding may reflect increased participation in cancer screening in the married patient population. We also found African Americans were more likely to be diagnosed in a later stage, consistent with the reported lower use of colon cancer screening in this population [6].

We also found a slightly higher chance of late stage diagnosis for females and a higher chance of early stage diagnosis for married men in a separate, gender-stratified analysis. Women are more likely to be attentive and assume responsibility of their husband's health than men are to their wife's [25]. Men not only are less likely to monitor their own health, but also the health and well being of their partners [26]. A study of breast cancer concluded women living alone may be more likely to monitor their own health and use the health system [27], which may explain the lower benefit of marriage in women.

Further research is needed to investigate why foreign born patients had better survival and earlier stage of diagno- 
sis. The shortcoming of the SEER dataset is that there is a large proportion of cases with unknown birth place. If this association is true, targeted intervention should be developed toward American born patients.

Although potentially influencing access to screening programs, we found no association between SES variables and survival or stage at diagnosis in the adjusted analysis. Although we did not use individual level SES data in our analysis as it is not available from SEER, the use of community level education and income data is common in SEER analysis $[17,18]$.

Our findings have implications in the prevention of colon cancer and in the analysis of colon cancer screening efficacy. Unmarried, especially single patients, are more likely to be diagnosed ( $11 \%$ higher risk) in later stages. Approximately half of people aged 50 years and older have been screened for colon cancer in the United States [28]. This study has identified a population at increased risk for late stage diagnosis partly due to decreased participation in screening. Targeted public health interventions can help alleviate this disparity and promote colon cancer screening participation among unmarried persons. The significant differences in mortality and stage at diagnosis between married and unmarried patients should also be accounted for in costeffectiveness analysis that includes colon cancer stage at diagnosis in the model.

\section{ACKNOWLEDGEMENT}

We would like to thank Prof. Shuang Wang, Aviva Geiger, Lauren Gross, and James Leahy for their comments, suggestions, preparation, and review of an early draft of this work.

\section{ABBREVIATIONS}

SEER $=$ Surveillance Epidemiology and End Results
AJCC $=$ American Joint Committee on Cancer
SES $=$ Socioeconomic Status
HR $=$ Hazard Ratio
OR $=$ Odds Ratio

\section{REFERENCES}

[1] American Cancer Society. Cancer Facts and Figures 2009.

[2] Screening for colorectal cancer: U.S. Preventive Services Task Force recommendation statement. Annals of Internal Medicine 2008; 149(9): 627-37.

[3] Bressler B, Lo C, Amar J, et al. Prospective evaluation of screening colonoscopy: who is being screened? Gastrointest Endosc 2004; 60(6): 921-6.

[4] Schenck AP, Peacock SC, Klabunde CN, Lapin P, Coan JF, Brown ML. Trends in colorectal cancer test use in the medicare population, 1998-2005. Am J Prev Med 2009; 37(1): 1-7.

[5] Kamposioras K, Mauri D, Golfinopoulos V, et al. Colorectal cancer screening coverage in Greece. PACMeR 02.01 study collaboration. Int J Colorectal Dis 2007; 22(5): 475-81.
[6] Rulyak SJ, Mandelson MT, Brentnall TA, Rutter CM, Wagner EH. Clinical and sociodemographic factors associated with colon surveillance among patients with a history of colorectal cancer. Gastrointest Endosc 2004; 59(2): 239-47.

[7] Sewitch MJ, Fournier C, Dawes M, et al. Do physician recommendations for colorectal cancer screening differ by patient age? Can J Gastroenterol 2007; 21(7): 435-8.

[8] van Jaarsveld CH, Miles A, Edwards R, Wardle J. Marriage and cancer prevention: does marital status and inviting both spouses together influence colorectal cancer screening participation? J Med Screen 2006; 13(4): 172-6.

[9] Johansen C, Schou G, Soll-Johanning H, Mellemgaard A, Lynge E. Influence of marital status on survival from colon and rectal cancer in Denmark. Br J Cancer 1996; 74(6): 985-8.

[10] Meguid RA, Slidell MB, Wolfgang CL, Chang DC, Ahuja N. Is there a difference in survival between right- versus left-sided colon cancers? Ann Surg Oncol 2008; 15(9): 2388-94.

[11] Kravdal O. The impact of marital status on cancer survival. Soc Sci Med 2001; 52(3): 357-68.

[12] Lai H, Lai S, Krongrad A, Trapido E, Page JB, McCoy CB. The effect of marital status on survival in late-stage cancer patients: an analysis based on surveillance, epidemiology, and end results (SEER) data, in the United States. Int J Behav Med 1999; 6(2): 150-76.

[13] Moghimi-Dehkordi B, Safaee A, Zali MR. Prognostic factors in 1,138 Iranian colorectal cancer patients. Int J Colorectal Dis 2008; 23(7): 683-8.

[14] Villingshoj M, Ross L, Thomsen BL, Johansen C. Does marital status and altered contact with the social network predict colorectal cancer survival? Eur J Cancer 2006; 42(17): 3022-7.

[15] O'Connell JB, Maggard MA, Ko CY. Colon cancer survival rates with the new American Joint Committee on Cancer sixth edition staging. J Natl Cancer Inst 2004; 96(19): 1420-5.

[16] AJCC Cancer Staging Manual, $6^{\text {th }}$ ed. Springer-Verlag New York, Inc. 2002.

[17] Roetzheim RG, Pal N, Tennant C, Voti L, Ayanian JZ, Schwabe A et al. Effects of health insurance and race on early detection of cancer. J Natl Cancer Inst 1999; 91(16): 1409-15.

[18] Reyes Ortiz CA, Freeman JL, Kuo YF, Goodwin JS. The influence of marital status on stage at diagnosis and survival of older persons with melanoma. J Gerontol 2007; 62(8): 892-8.

[19] Robinson E, Mohilever J, Zidan J, Sapir D. Colorectal cancer: incidence, delay in diagnosis and stage of disease. Eur $\mathrm{J}$ Cancer Clin Oncol 1986; 22(2): 157-61.

[20] Neal RD, Allgar VL. Sociodemographic factors and delays in the diagnosis of six cancers: analysis of data from the "National Survey of NHS Patients: Cancer". Br J Cancer 2005; 92(11): 1971-5.

[21] Langenbach MR, Schmidt J, Neumann J, Zirngibl H. Delay in treatment of colorectal cancer: multifactorial problem. World J Surg 2003; 27(3): 304-8.

[22] Yi JK. Factors associated with cervical cancer screening behavior among Vietnamese women. J Commun Health 1994; 19(3): 189200.

[23] Osborne C, Ostir GV, Du X, Peek MK, Goodwin JS. The influence of marital status on the stage at diagnosis, treatment, and survival of older women with breast cancer. Breast Cancer Res Treat 2005; 93(1): 41-7.

[24] Nayeri K, Pitaro G, Feldman JG. Marital status and stage at diagnosis in cancer. NY State J Med 1992; 92(1): 8-11.

[25] Umberson D. Gender, marital status and the social control of health behavior. Soc Sci Med 1992; 34(8): 907-17.

[26] Nathanson CA. Sex roles as variables in preventive health behavior. J Commun Health 1977; 3(2): 142-55.

[27] Moritz DJ, Satariano WA. Factors predicting stage of breast cancer at diagnosis in middle aged and elderly women: the role of living arrangements. J Clin Epidemiol 1993; 46(5): 443-54.

[28] Neugut AI, Lebwohl B. Screening for colorectal cancer: the glass is half full. Am J Public Health 2009; 99(4): 592-4.

(C) Lai and Stotler; Licensee Bentham Open.

This is an open access article licensed under the terms of the Creative Commons Attribution Non-Commercial License (http://creativecommons.org/licenses/by-nc/3.0/) which permits unrestricted, non-commercial use, distribution and reproduction in any medium, provided the work is properly cited. 